\title{
CHEMOSENSITIZER EFFECT OF THE CRUDE OIL WATER-SOLUBLE FRACTION ON MULTIXENOBIOTIC RESISTANCE MECHANISM OF THE MUSSEL PERNA PERNA EXPOSED TO TRIBUTYLTIN
}

\author{
JAKOBI, S. C. G. ${ }^{1}$; RIBEIRO, C. A. O. ${ }^{2}$; BURCKHARDT, P. L. ${ }^{3}$; OLIVEIRA, L. T. ${ }^{3}$ \& PESSATTI, M. L. ${ }^{3 *}$ \\ 1 - Superintendencia de Recursos Hídricos - SEMA/MT \\ 2 - Laboratory of Cellular Toxicology, Department of Cell Biology, Federal University of Paraná \\ 3 - Centro de Ciências Tecnológicas da Terra e do Mar, Universidade do Vale do Itajaí \\ *Corresponding author: pessatti@univali.br
}

\begin{abstract}
Jakobi, S. C. G.; Ribeiro, C. A. O.; Burkhardt, P. L.; Oliveira, L. T. \& Pessatti, M. L. (2012) Chemosensitizer effect of the crude oil water-soluble fraction on multixenobiotic resistance mechanism of the mussel Perna perna exposed to tributyltin. Braz. J. Aquat. Sci. Technol. 16(1): 69-77. eISSN 1983-9057. Tributyltin (TBT) and Water-Soluble Fraction (WSF) of crude oil are usually present in estuarine coastal waters. The transport of rhodamine B by multixenobiotic resistance (MXR) mechanism and Scanning Electron Microscopy (SEM) analysis were used for the experimental evaluation of the individual and associated sublethal effects of TBT and WSF on the gills of Perna perna. The combined effects of WSF and TBT were studied. A set of experiments consisted in testing $25 \mathrm{ng}$ TBT/L and different WSF concentrations, whereas another set consisted in assays with $33 \%$ WSF and different TBT concentrations. The results showed an inhibition in the MXR transport activity of mussels exposed to 75 and $100 \%$ of WSF, while the concentration upper than $300 \mathrm{ng}$ TBT/L induced the same mechanism. The results showed that TBT increases the effect of WSF when they are exposed together. Morphological analysis showed gills lesions only in the group of WSF. The observed disturbs were due to the organization of cilia on the surface of the lamellae with potential consequence to feed and gas exchange.
\end{abstract}

Keywords: TBT, Crude oil Water-Soluble Fraction, MXR, ecotoxicology.

\section{INTRODUCTION}

Several compounds released to aquatic environments are potentially toxic to biota, and the majority of them have been considered global pollutants, as they can be easily dispersed into the environment. Both tributyltin (TBT) and crude oil compounds constitute contaminants in harbor and costal areas influenced by navigation activities. The production of tin compounds, such as TBT, has an estimated annual production of around 60.000 tons (Souza et al., 2009). These compounds were widely applied in the past decades as components of antifouling paints for boats. Notwithstanding they were banished since 2008, their impacts still persist in marine ecosystems. Besides, TBT is considered an important pollutant to estuarine ecosystems (Fent, 1996) due to its high potential toxicity (Pádros et al., 2003) and easy dispersion within marine environments. Lee (1996) reported that mussels can accumulate high concentrations of TBT when naturally exposed to the substance. Tributyltin is also an endocrine disruptor (Takeda et al., 2009), yonder be a cytochrome P450 enzymatic system inhibitor that makes the organism most sensible to other toxic xenobiotics (Fent, 1996).

The increased utilization of crude oil and its derivates for industrial and human activities, as transport and energy source, substantially increased their consumption worldwide in the last century. These intense activities have resulted in chronicle releasing to environment and in accidents involving oil spill and the release of toxic chemicals to aquatic environments. Overall, the development of effective methods for the evaluation of crude oil impact on the biota and human populations still remains as a challenging task for environmental scientists. According to Neff (1978), 75\% of the constituents of crude oil are hydrocarbons of long and short chains. The short chain hydrocarbons are more toxic than larger chain ones; besides, they are more volatile and remain for shorter periods in aquatic environment (Brauner et al., 1999). However, Saeed \& Mutairi (1999) reported that after accidental oil spill, water-soluble fraction (WSF) of crude oil was the most important cause of the acute effects on aquatic organisms.

Morphological studies constitute a rapid and reliable method for the detection of acute and chronic effect due to chemical exposure to aquatic organisms. Additionally, when associated with others biomarkers, the results are more efficient (Hinton et al., 1992).

The multixenobiotic resistance mechanism (MXR) has been consolidated as a molecular biomarker of exposure, constituting a natural "first line" biological mechanism of defense for protection against endogenous and environmental toxins in aquatic organisms (Kurelec et al., 1997; Epel, 1998). This mechanism is analogous to the multidrug resistance mechanism (MDR), described in tumoral cells of 
mammals by Juliano \& Ling (1976). Both have been described to carry to the extracellular mean, compounds recognized as xenobiotic. In this manner, MXR mechanism represent an important ecotoxicological role in the residential time of cellular pollutants after uptake, which results in the rates of bioaccumulation and toxicity of pollutants (Kurelec et al., 1997). Also, assays of associated effects can investigate a new kind of effect and disclose the compounds pertaining to a novel class of contaminants: the cellular chemosensitizers. These compounds can block the function of transport activity, decreasing the capacity of efflux xenobiotics or endogenous compounds from the cell (Kurelec, 1992; Achard et al., 2004; Zaja et al., 2008). To the study of this transport activity, have been intensively used substrates fluorophores of the MXR, among which the rhodamine B (Cornwall et al., 1995; Pessatti et al., 2002), which can be used as a marker as much accumulated as effluxed.

The use of SEM to evaluate damages on cells and tissues of gills in aquatic organisms are a very well established tools as described by Akaishi et al. (2004) and Brito et al. (2012) in fish and Valdez Domingos et al. (2007) in oysters.

This study has investigated the isolated and associated effects of WSF of crude oil and TBT on the transport activity of MXR in P. perna after experimental exposure, and also the effects of these compounds on gill morphology through scanning electronic microscope (SEM).

\section{MATERIALS AND METHODS}

\section{Animals}

Adults of brown mussel Perna perna (between 5 and $7 \mathrm{~cm}$ lengths) were collected from the Itapocoroy beach, Penha, Santa Catarina State - South of Brazil (Fig. 1). As the gender does not modify the standard activity of MXR complex (Pessatti et al., 2002), both male and female individuals were used. After sampling, the animals were washed and kept in aquaria (2.5 individuals per liter) for acclimatization for at least five days, in filtered seawater, before the experiments. They were maintained with constant aeration, in a 12 hours photoperiod regime, and fed daily with Chaetoceros gracilis, cultivated in our own laboratory. The aquaria were cleaned every two days.

\section{Water Solution Fraction (WSF) of Crude Oil}

The WSF was obtained according to the method of Anderson et al. (1974). The samples of crude oil were obtained at the Getúlio Vargas Refinery - REPAR (Petrobrás Oil Company) Paraná State, and were

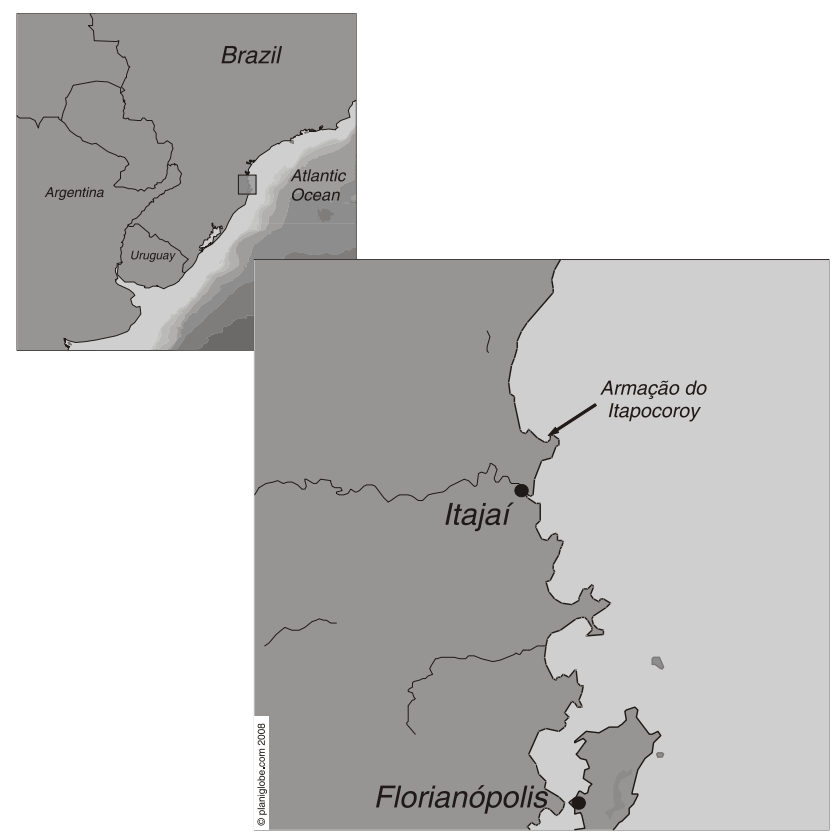

Figure 1 - Location of the study area. Detail shows the Experimental Station of Marine Culture of the Universidade do Vale do Itajai (UNIVALI), Armação do Itapocoroy, Penha - SC, Brazil.

original from the Petroliferous Basis of Campos, Rio de Janeiro State, Brazil.

\section{Bioassays}

Four experiments were carried out to investigate the effects of WSF and TBT on MXR activity. First, the effect of each contaminant on MXR was investigated initially in separate, in three individuals per concentration, for a period of exposure of 24 hours under constant aeration and temperature. The assay to determination of WFS effect was carried out with dilutions of WSF 15, $25,33,50,75$ e $100 \%$. In other assay, to determination of TBT effect, were used the concentrations of 25,55 , 100,300 and $500 \mathrm{ng} / \mathrm{L}$ of the contaminant. The tested concentrations of TBT were based on the data from impacted environments (Fent, 1996; Tong et al., 1996) and the dilutions of WSF were prepared according to Anderson et al. (1974). To investigate the associated effects of TBT and WSF on MXR mechanism of $P$. perna, the dilution of WSF (33\%) and TBT concentration $(25 \mathrm{gg} / \mathrm{L})$, i.e., those concentrations with lower effects on MXR transport activity, were respectively associated with the tested concentrations of TBT and dilutions of WSF as described above.

Assay of rhodamine $B$ efflux by MXR mechanism

The mechanism of MXR efflux was determined according to Cornwall et al. (1995) with the modifications proposed by Pessatti et al. (2002). The gills were sampled after the anesthesia of mussels on ice and transferred to filtered sea water. Sections of 25 $\mathrm{mm} 2$ of the secondary lamellae were obtained from 
each lamella and incubated in rhodamine B $1 \mu \mathrm{mol} / \mathrm{L}$ (prepared with the same experimental seawater salinity) for 60 minutes. The sections were removed and placed in the clean seawater to observe the efflux of rhodamine $\mathrm{B}$. For the control groups, $0.5 ; 5 ; 15 ; 30$ and 60 minutes were considered as efflux time, and for the tested groups, only 5 and 15 minutes were considered.

The fluorescence intensities of gill sections were measured using a fluorescence microscope Olympus BX60 equipped with filter U-MWG (filter of $510-550$ nm excitement and filter of emission blockade of 590 ทm).A photo sensor Olympus PM20 connected with the microscope was used for the quantification of emitted light. The quantified fluorescence as exposure time by photo sensor reflects the intracellular concentration of fluorophore (rhodamine B). It was prevented by the interfilamentar connective tissue from varying thickness and fluorescence (Cornwall et al., 1995). With the diaphragm closed and focused on only one branchial filament at a time, the fluorescence intensities of 30 filaments were measured.
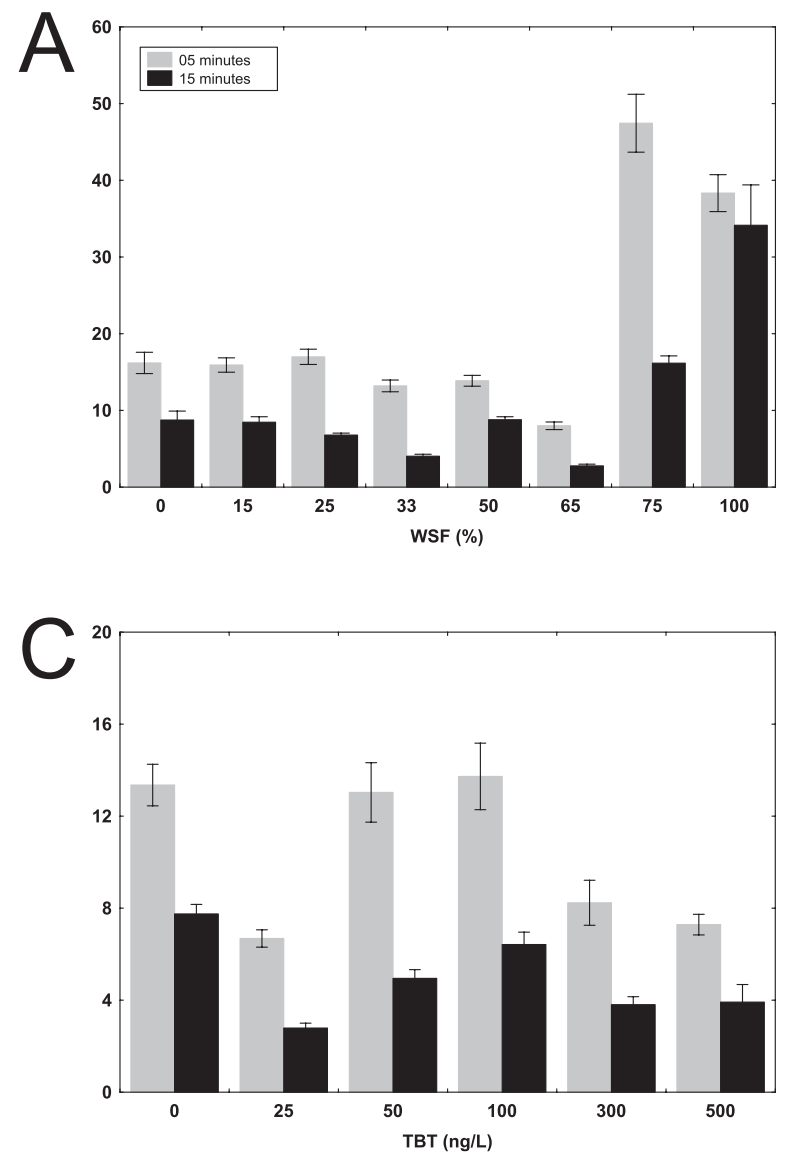

\section{Scanning Electron Microscopy (SEM) Analysis}

For SEM analysis, gills were first removed, fixed in glutaraldehyde $(3 \%)$, cacodilate buffer $0,1 \mathrm{M}(\mathrm{pH}$ $7.2-7.4$ ) for at least 24 hours, dehydrated in ethanol (Merck) and liquid $\mathrm{CO}_{2}$ (critical point), covered with gold and observed through Scanning Electronic Microscopic Philips SEM550.

\section{Statistics Analysis}

Analysis of Variance (ANOVA) followed by Tukey multiple comparison, were performed for statistical analysis, with significance level of $95 \%$.

\section{RESULTS}

The highest variation in MXR activity was observed in those individuals exposed to dilutions of 75 and $100 \%$ WSF, when compared with the control group. Actually, the variations in MXR activity between the groups were minimal (Fig. 2) until exposure to $50 \%$
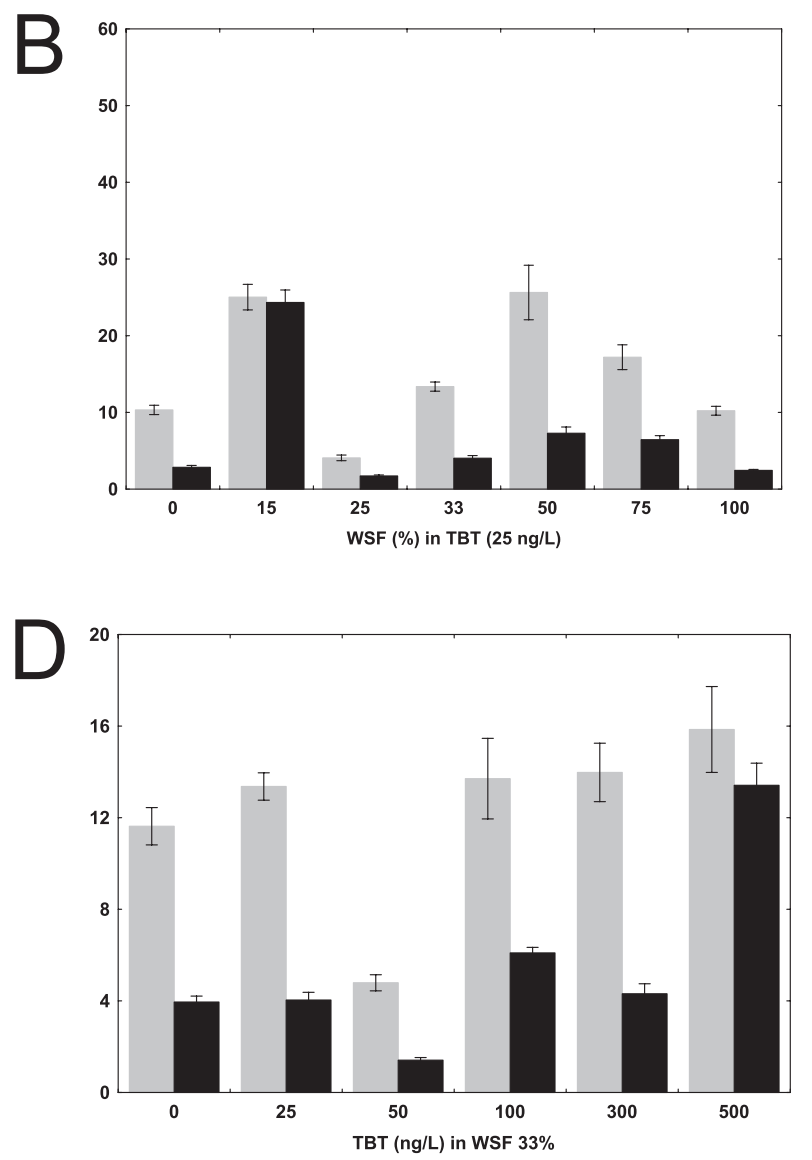

Figure 2 - Accumulation of rhodamine $B(n$ moles/L) in gills of mussels exposed to the WSF (A), TBT (C) and associations (B and D). A- The results showed a stimulation of the MXR mechanism after dilution of $75 \%$ at five and fifteen minutes of efflux time. B - When exposed to TBT $(25 \mathrm{ng} / \mathrm{L})$ with different concentration of WSF dilutions, was observed an increase in rhodamine B efflux after five and fifteen minutes of efflux time, but decreasing at WSF $100 \%$ after fifteen minutes. C - Observe that differently of WSF, the TBT decrease the activity of MXR after $300 \mathrm{ng} / \mathrm{L}$ at five and fifteen minutes of efflux time. D - When exposed to WSF (33\%) with different concentrations of TBT, is observed an increase of rhodamine B efflux only in $300 \mathrm{ng} / \mathrm{L}$ of TBT at fifteen minutes of efflux time. 

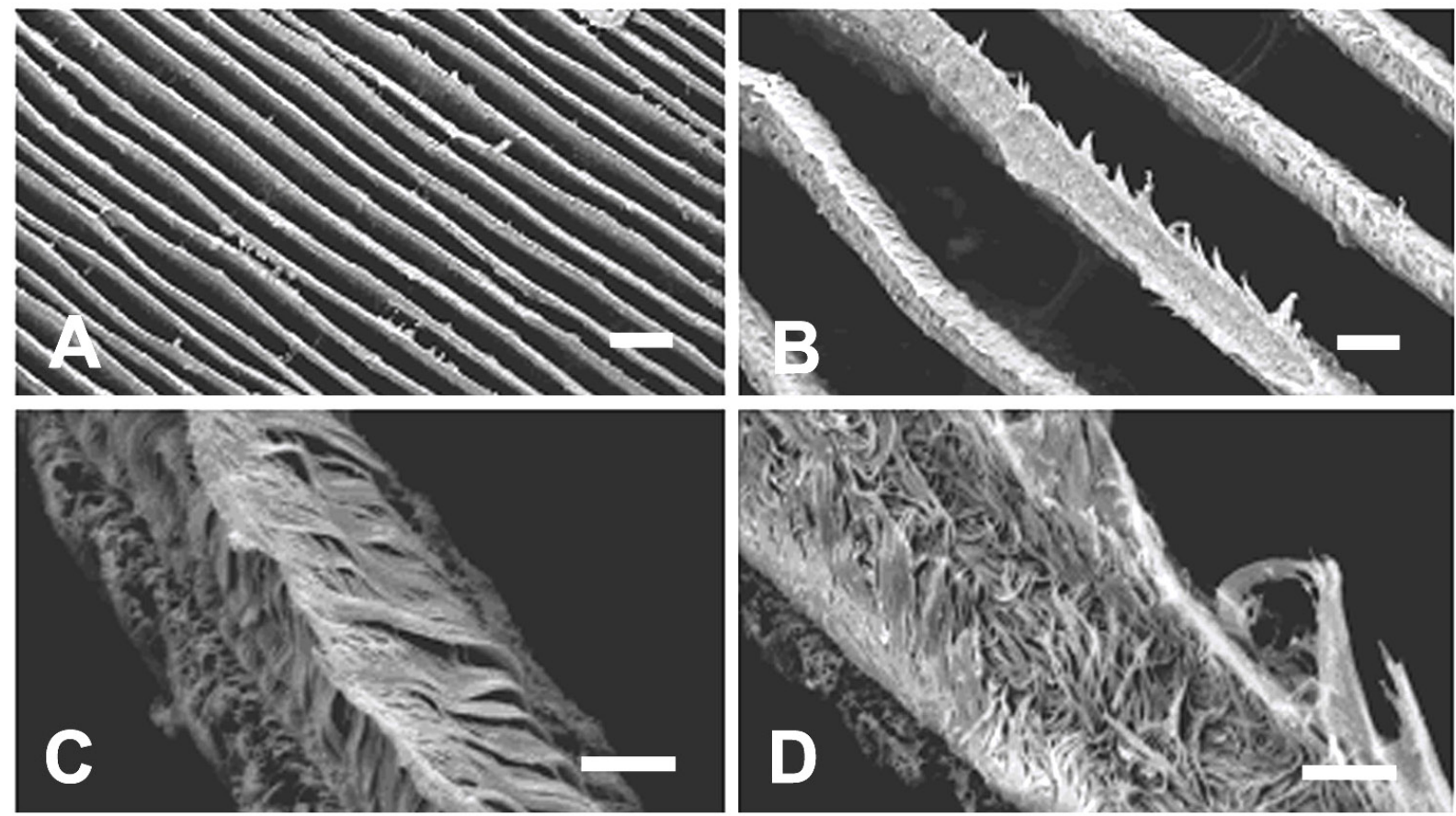

Figure 3 - Scanning Electron Microscopy of gill from Perna perna. Control group. A - General view of the gill. Scale bar = 100 $\mu$ m. B Individual lamellae. Scale bar $=20 \mu \mathrm{m}$. C and D - Details of the individual lamellae surface with "open" and "closed" channel recovered by cilia to transport food. Scale bar $=5 \mu \mathrm{m}$.

dilution. Moreover, under this condition, an increase in the transport activity of rhodamine B was observed, as expressed by the decrease in accumulation due to higher efflux. In those animals exposed to TBT, the transport activity of rhodamine B from all groups decreased significantly from the 15 minutes-control; however, the group exposed to $100 \mathrm{ng} / \mathrm{L}$ markedly differed from all other groups in terms of lower efflux rate (expressed as higher accumulation) of rhodamine B (Fig. 2). In relationship to control, the data of TBT showed stimulation in MXR activity for all tested concentrations.

The group that presented the highest variation $(p<0.05)$ from the other groups was that exposed to TBT associated with $15 \%$ WSF (Fig. 2). All treatments, except those of 25 and $100 \%$ WSF, resulted in lower MXR transport activity than the control group. Lower transport activity of WSF indicates higher accumulation and vice versa. The highest MXR inhibition was observed with 15 and $50 \%$ WSF, as expressed by higher accumulation (lower efflux). After the exposure of mussels to $33 \%$ WSF (fixed) and simultaneously to varying concentrations of TBT (15 minutes of efflux time), the rhodamine $B$ transport activity was increased in relationship to control group (Fig. 2). Exceptions were observed for 25 and $300 \mathrm{ng} / \mathrm{L}$. Thus, with $50 \mathrm{ng} / \mathrm{L}$, an increase in efflux activity was observed, whereas both 100 and $500 \mathrm{ng} / \mathrm{L}$ TBT resulted in decreased efflux activity, as expressed by higher accumulation (Fig. 2).

The exposure to TBT $(25 \mathrm{ng} / \mathrm{L})$ increased thrice the WSF effect (when compared to WSF alone) (Table 1 ), while exposure to WSF (fixed at $33 \%$ ) increased the TBT effect between 0.42 and 6.72 times, when compared to TBT alone (Table 2).

The morphological analysis using Scanning Electronic Microscopy showed uniform branchial filaments in the individuals from the control group. The filaments are adjacently disposed revealing a highly organized structure (Fig. 3A). The surface of the filament is covered by innumerous cilia that come toward the axis along the filament (Fig. 3B and C) or open forming a small depression along the filament (Fig. 3B and D).

Table 1 - Sensitizer effect of TBT in Perna perna gill exposed to WSF. The efflux activities of WSF ( 5 and 15 minutes) as much in absence as presence of TBT ( $25 \mathrm{ng} / \mathrm{L}$ ) were estimated relatives to respective controls (without WSF neither TBT). The sensitizer effect of TBT was estimated for the ratio between the efflux in the presence of TBT in relationship to absence (only WSF).

\begin{tabular}{llllll}
\hline \hline & \multicolumn{5}{c}{ WSF (\%) } \\
\cline { 2 - 6 } & $\mathbf{2 5}$ & $\mathbf{3 3}$ & $\mathbf{5 0}$ & $\mathbf{7 5}$ & $\mathbf{1 0 0}$ \\
\hline WSF 05'+TBT 25ng/L:WSF alone & 0.38 & 1.59 & 2.90 & 0.57 & 0.42 \\
WSF 15'+TBT 25ng/L:WSF alone & 0.78 & 3.08 & 2.55 & 1.23 & 0.22 \\
\hline \hline
\end{tabular}


Table 2 - Sensitizer effect of WSF in Perna perna gill exposed to TBT. The efflux activities of TBT (5 and 15 minutes) as much in absence as presence of WSF $33 \%$ were estimated relatives to respective controls (without TBT neither WSF). The sensitizer effect of WSF was estimated for the ratio between the efflux in the presence of WSF in relationship to absence (only TBT).

\begin{tabular}{lccccc}
\hline \hline & \multicolumn{5}{c}{ TBT (ng/L) } \\
\cline { 2 - 6 } & $\mathbf{2 5}$ & $\mathbf{5 5}$ & $\mathbf{1 0 0}$ & $\mathbf{3 0 0}$ & $\mathbf{5 0 0}$ \\
\hline TBT 05'+WSF 33\%:TBT alone & 2.30 & 0.42 & 1.15 & 1.95 & 2.50 \\
TBT 15'+WSF 33\%:TBT alone & 2.84 & 0.56 & 1.86 & 2.22 & 6.72 \\
\hline \hline
\end{tabular}

Severe damages were found in individuals exposed to both contaminants (Fig. 4A and 5A) isolated or together. The current data demonstrated that under WSF dilutions by keeping fixed TBT concentration, and it was observed that under WSF (15\%), partial disorganization of the cilia (Fig. 4B) was observed but after exposure to $25 \%$ of WSF, the alterations were more evident reaching up to a total disorganization of cilia. Observe that the channel present in Figure 3 is not found (Fig. 4C) and a complete fusion among various filaments is present in this group (Fig. 4D). Simillar effects could be found in individuals from group exposed to $100 \%$ WSF (Fig. 4E and 4F), but less severe damages were observed when the individuals were exposed to a constant dilution of WSF (33\%) associated with different TBT concentrations (Fig. 5). After exposure to $25 \mathrm{ng} / \mathrm{L}$ of TBT, a disorganization of cilia became more evident (Fig. 5B) and a complete fusion
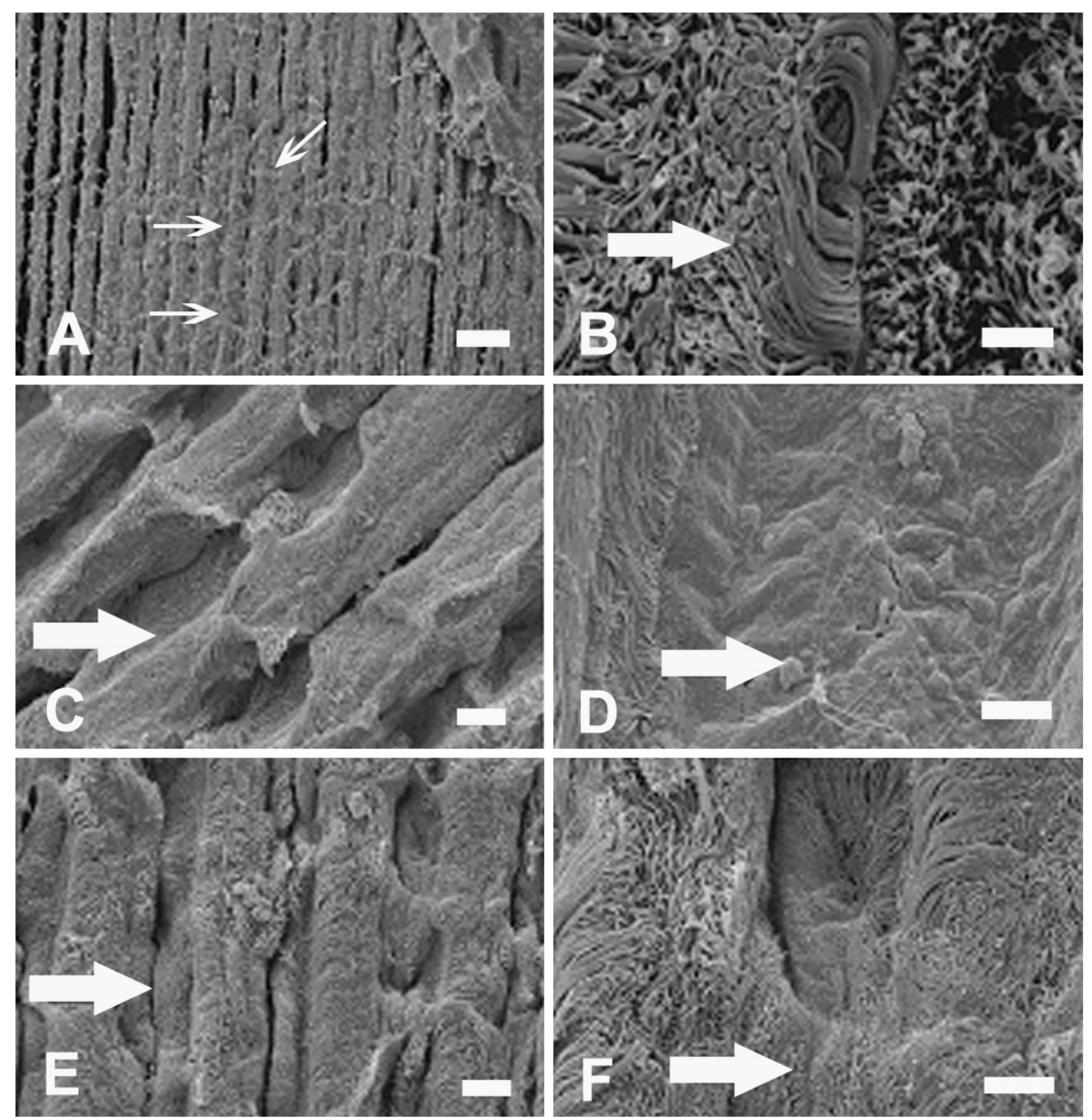

Figure 4 - Scanning Electron Microscopy of gill from Perna perna after TBT (25ng/L) associated with different dilutions of Water-Soluble Fraction (WSF) of crude oil. A - TBT+100\% WSF. Observe the lamellae fusion (arrows). Scale bar $=100 \mu \mathrm{m}$. B - Detail of gills under TBT $+15 \%$ WSF exposure. Arrow shows the ciliar disorganization. Scale bar $=5 \mu \mathrm{m}$. C and D $-\mathrm{TBT}+25 \%$ WSF. Respectively observe the cilia disorganization (arrow) and the total fusion between lamellae (arrow). Scale bar $=20$ and $5 \mu \mathrm{m}$ respectively. $E$ and $F-T B T+100 \%$ WSF. Observe the increase of cilia and consequently surface disorganization. Scale bar $=20$ and $10 \mu \mathrm{m}$ respectively. 

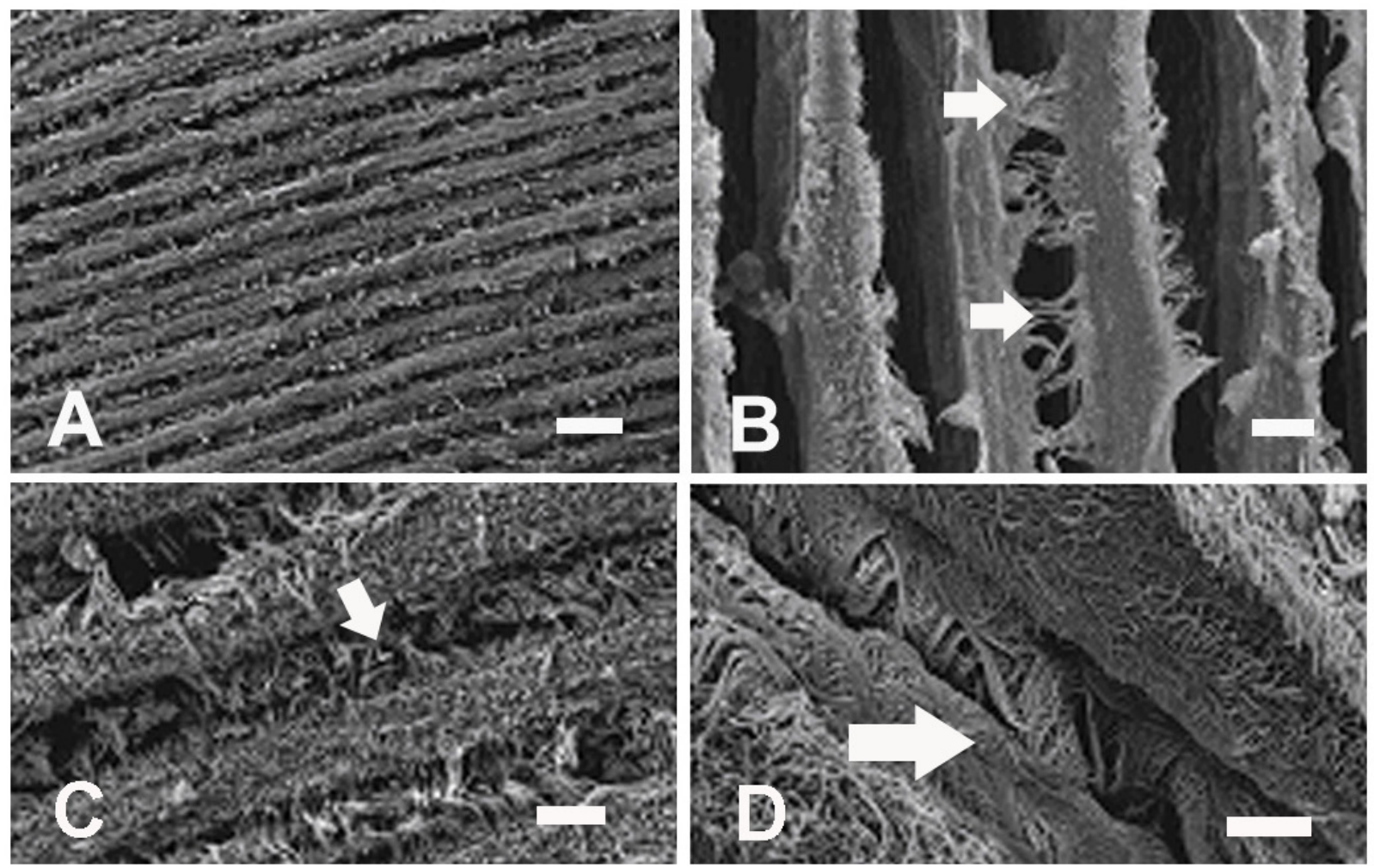

Figure 5 - Scanning Electron Microscopy of gill from Perna perna after WSF (33\%) associated with different concentrations of TBT. A WSF+100ng/L TBT. Scale bar $=100 \mu \mathrm{m} . \mathrm{B}-\mathrm{WSF}+25 \mathrm{ng} / \mathrm{L}$ TBT. Observe the ciliar disorganization and the cross bridges between lamellas (arrows). Scale bar $=20 \mu \mathrm{m} . \mathrm{C}$ and D $-\mathrm{WSF}+100 \mathrm{ng} / \mathrm{L} \mathrm{TBT}$. Observe the increase on ciliar disorganization (arrows). Scale bar $=20$ and $10 \mu \mathrm{m}$ respectively.

of filaments is present in gills. Both Figures $5 \mathrm{C}$ and 5D show the extension of damages on filaments structure after few hours of exposure to $100 \mathrm{ng} / \mathrm{L}$ of TBT.

\section{DISCUSSION}

Tributyltin and water-soluble fraction (WSF) of crude oil can be easily found in estuaries, where harbor and urban activities are installed. Therefore, both individual and associated studies are vital to understand their potential toxicity to individual, population or marine ecosystem. The use of Perna perna as a model to investigate the effects of both contaminants is particularly efficient because of its known biological characteristics such as wide distribution, abundance (particularly in Brazilian coast) and resistance to many contaminants (Pessatti et al., 2002).

Tributyltin is a known toxic compound and although its effects have been studied in aquatic organisms (Rabitto et al., 2005; Roach \& Wilson, 2009), little information regarding to the effects of TBT on MXR mechanism is available (Kingtong et al., 2007). Achard et al. (2004) studied the effect of some metals such as zinc, copper, inorganic mercury and cadmium on the Pgp of Corbicula fluminea. They found a posi- tive relationship between the levels of MXR and metal exposure. Downs \& Downs (2007) found the same effects in coral Madracis mirabilis exposed to Irgarol 1051. Verifying the function of MXR on detoxifying TBT, Kingtong et al. (2007) established the relationship between the MDR1, MRP1 and BCRP expression, the transport activity of these proteins and levels of TBT in Saccostrea forskali, suggesting a cellular stress response to TBT.

The exact mechanism for the effects of heavy metals on the transport activity of MXR is not clearly known. There are two hypotheses: a) an increase (Chin et al., 1990) or a down-regulation (Kobayashi-Hattori et al., 2006) in MDR1 gene expression codifying Pgp, and $b$ ) an increase (or decrease, depending of metal) in the transport activity of Pgp (or correlated proteins, as MRP - multidrug resistance associated-protein).

In relation to WSF, the effects of PAHs on MXR function have been widely described. According to Smital \& Kurelec (1998), Rougée et al. (2006) and others, PAHs, oil diesel and crude oil can induce MXR expression (Bard et al., 2002). In this study, the efflux rate of gills exposed to WSF up to $25 \%$ was similar to that observed in the control group. Under these conditions, the basal cellular mechanisms appear to be enough to detoxification. 
The establishment of the effects of various contaminants on aquatic organisms is one of the biggest challenges in ecotoxicology. All information concerning the multiple effects is important to understand the real impact of contaminants on aquatic organisms. In this sense, the MXR function was not inhibited by only WSF until $65 \%$. However, when the individuals were continuously exposed to TBT (25 ng/L), the effect of WSF on the efflux of rhodamine $B$ was changed. When simultaneously exposed at $25 \%$ WSF, TBT appeared to have a stimulatory effect on MXR activity. However, at $33 \%$ and $50 \%$, the sensitizer effect of TBT was revealed, as demonstrated by the higher accumulation of rhodamine B (efflux decrease) (Table 1). This result suggests a 'chemosensitizer' effect (Kurelec, 1992) of TBT on those individuals exposed to both contaminants. This information is important, therefore requires further investigation.

On the other hand, the sensitizer effect of WSF on MXR activity was clearly evident when combined with TBT. In a dose-dependent manner, the WSF decreased the MXR activity in until 6.7 times, as observed in higher tested TBT concentration (Table 2). These results show that, although WSF $33 \%$ has a subtle effect on MXR transport activity (Fig. 2), minor concentrations of WSF can sensitize the cell to other environmental contaminants, as observed when associated with TBT.

Few data concerning to morphological effects of WSF on the branchial tissues of mussels are available because the majority of studies are focusing on fish species. The majority of studies were focused on fish species. According to Gregory et al. (1999), Perna perna exposed to mercury for a long time showed the occurrence of necrosis areas and absence of eyelashes. Sub chronic and chronic exposures can favor the presence of this type of lesion, but they were not observed in this study. Comparatively, the lesions described in the present study are apparently less severe, but can still affect feeding and gas exchange. The morphological damages observed in this study do not clearly indicate the synergism of TBT on WSF effects, but can affect the normal function of the gills of Perna perna, after isolated or associated exposure.

\section{CONCLUSION}

Notwithstanding the relevance of the tested contaminants in this study, its isolated and/or associated effects on MXR transport activity are still less explored in ecotoxicology. The morphological alterations observed in the gill of Perna perna did not substantiate the same effects described for MXR function, but showed important lesions that could interfere with the physi- ological gill function. TBT and WSF presented effects on the transport of rhodamine B by MXR mechanism, but further studies are required to better understand the effect of these as well as other classes of contaminants on the resistance mechanisms of the cell. The exposure to TBT showed stimulation on the transport activity by MXR, whereas WSF showed an inhibitory effect at higher concentrations (75 and 100\%). The association of both contaminants indicated that WSF can act as a cellular sensitizer, thereby increasing the inhibitory effect of other contaminants such as TBT on MXR transport activity.

\section{REFERENCES}

Achard, M.; Baudrimont, M.; Boudou, A. \& Bourdineaud, J. P. 2004. Induction of a multixenobiotic resistance protein (MXR) in the Asiatic clam Corbicula fluminea after heavy metals exposure. Aquat. Toxicol. 67: 347-357.

Akaishi, F.M.; de Assis, H.C.; Jakobi, S.C.; EirasStofella, D.R.; St-Jean, S.D.; Courtenay, S.C.; Lima, E.F.; Wagener, A.L.; Scofield, A.L.; Oliveira Ribeiro, C.A. 2004. Morphological and neurotoxicological findings in tropical freshwater fish (Astyanax sp.) after waterborne and acute exposure to water soluble fraction (WSF) of crude oil. Arch. Environ. Contam. Toxicol. 46(2): 244-53.

Anderson, J. W.; Neff, J. M.; Cox, B. A.; Tatem, H. E. \& Hightower, G. M. 1974. Characteristics of dispersion and water-soluble extracts of crude and refined oil and their toxicity to estuarine crustaceans and fish. Mar. Biol. 27: 75-88.

Bard, S. M.; Woodin, B. R. \& Stegemam, J. J. 2002. Expression of P-glycoprotein and cytochrome P450 $1 \mathrm{~A}$ in interdital fish (Anoplarchus purpuresces) exposed to environmental contaminats. Aquat. Toxicol. 60: 17-32.

Brauner, C. J.; Ballantyne, C. L.; Vijayan, M. M. \& Val, A. L. 1999. Crude oil exposure affects air breathing frequebcy, blood phosphate levels and ion regulation in an air - breathing teleost fish, Hoplosternun littorale. Comp. Biochem. and Phisiol. 123: 127-134.

Brito, I.A; Freire,C.A.; Yamamoto, F.Y.; de Assis, H.C.S.; Souza-Bastos, L.R.; Cestari, M.M.; Ghisi, N.C; Prodocimo, V.; Filipak Neto, F.; Oliveira Ribeiro, C.A. 2012. Monitoring water quality in reservoirs for human supply through multi-biomarker evaluation in tropical fish. J. Environ. Monit. 14: 615.

Chin, K. V.; Tanaka, S.; Darlington, G.; Pastan, I. \& Gottesman, M. M. 1990. Heat shock and arsenite increase expression of multidrug resistance 
(MDR1) gene in human renal carcinoma cells. J. Biol. Chem. 265, n. 1: 221-226.

Cornwall, R.; Toomey, B. H.; Bard, S.; Bacon, C.; Jarman, W. M. \& Epel, D. 1995. Characterization of multixenobiotic/multidrug transport in the gills of the mussel Mytilus californianus and identification of environmental substrates. Aquat. Toxicol. 31: 277-296.

Downs, C. \& Downs, A. 2007. Preliminary examination of short-term cellular toxicological responses of the coral Madracis mirabilis to acute Irgarol 1051 exposure. Arch. Environ. Contam. Toxicol. 52(1): 47-57.

Epel, D. 1998. Use of multidrug transportes as first lines of defense against toxins in aquatic organisms. Comp. Biochem. Physiol. 120: 23-28.

Fent, K. 1996. Ecotoxicology of Organotin Compoumds, Crit. Rev. Toxicol. 26(1): 1-117.

Gregory, M. A.; George, R. C.; Marshall, D. J.; Anadraj, A \& Mcclurg, T. P. 1999. The effects of mercury exposure on the surface morphology of gill filaments in Perna perna (Mollusca: bivalvia). Mar. Pollut. Bull., 39 (1-12): 116-121.

Hinton, D. E.; Baumann, P. C.; Gardner, G. R.; Hawkins, W. E.; Hendricks, J. D.; Murchelan, R. A. \& Okihiro, M. S. 1992. Histopathologic biomarkers. In: Huggett, R. J. (ed.) Biomarkers: Biochemical, Physiological and Histological Markers of Antropogenic Stress. Lewis Publishers. 155-208pp.

Juliano, R. L. \& Ling, V. 1976. A surface glicoprotein modulating drug permeability in chinese hamster ovary cell mutants. Biochim. Biophis. Acta 455: 152-162.

Kingtong, S.; Chitramvong, Y. \& Janvilisri, T. 2007. ATP-binding cassette multidrug transporters in Indian-rock oyster Saccostrea forskali and their role in the export of an environmental organic pollutant tributyltin. Aquat. Toxicol. 85: 124-132.

Kobayashi-Hattori, K.; Watanabe, T.; Kimura, K. \& Sugita-Konishi, Y. 2006. Down-regulation of $\mathrm{mdr} 1 \mathrm{~b}$ mRNA expression in the kidneys of mice following maternal exposure to tributyltin chloride. Biosci. Biotechnol. Biochem. 70(5): 1242-5.

Kurelec, B. 1992. The multixenobiotic resistence mechanism in aquatic organisms. Crit. Rev. Toxicol. 22(1): 23-43.

Kurelec, B.; Smital, T.; Britvic, S.; Pivcevic, B.; Krca, S.; Jelaska, S. B.; Sauerborn, R. \& Mustajbegovic, S. 1997. Multixenobiotic defense mechanism in aquatic organisms. Period. Biolog. 99(3): 319-328.

Lee, R. F. 1996. Metaboliesm of tributyltin by aquatic organisnms. In: Champ M.A. and Seligman, P.F. (eds.) Organotin: Environmetal Fate and Effects. London: Chapman \& Hall. 369-382pp.
Neff, H. M. 1978. Polycyclic aromatic hydrocarbons in the aquatic environmet souces, fates and biological effects. Applied Science Publishers Ltd. Essex: UK.

Padrós, J.; Pelletier, E. \& Ribeiro, C.O. 2003. Metabolic interactions between low doses of benzo[a]pyrene and tributyltin in arctic charr (Salvelinus alpinus): a long-term in vivo study. Toxicol. Appl. Pharmacol. 192(1) : 45-55.

Pessatti, M. L.; Resgalla J. R. C.; Reis F. R. W.; Kuehn, J.; Salomão, L. C. \& Fontana, J. D. 2002. Variability of filtration and food assimilation rates, respiratory activity and multixenobiotic resistance (MXR) mechanism in the mussel Perna perna under lead influence. Braz. J. Biol. 62(4A): 651-656.

Rabitto, I. S.; Costa, J. R. M. A.; Assis, H. C. S.; Akaishi, F. M.; Pelletier, E. \& Oliveira Ribeiro, C. O. 2005. Dietary $\mathrm{Pb}(\mathrm{II})$ and TBT (tributyltin) exposures to neotropical fish Hoplias malabaricus: histopatological and biochemical findings. Ecotox. Environ. Saf. 60:147-156.

Roach, A. C. \& Wilson, S. P. 2009. Ecological impacts of tributyltin on estuarine communities in the Hastings River, NSW, Australia. Mar. Pollut. Bull. 58: 1780-1786.

Rougée, L.; Downs, C. A.; Richmond, R. H. \& Ostrander, G. K. 2006. Alteration of normal cellular profiles in the Scleractinian coral (Pocillopora damicornis) following laboratory exposure to fuel oil. Environ. Toxicol. Chem. 25(12): 3181-3187.

Saeed, T. \& Mutairi, M. A. 1999. Chemical composition of the water soluble fraction of leaded gasolines in seawater. Environ. Int. 25: 117-129.

Smital, T. \& Kurelec, B. 1998. The chemosensitizers of multixenobiotic resistance mechanism in aquatic invertebrades: a new class of pollutants. Mut. Res. 399: 43-53.

Sousa, A.; Ikemoto, T.; Takahashi, S.; Barroso, C. \& Tanabe, S. 2009. Distribution of synthetic organotins and total tin levels in Mytilus galloprovincialis along the Portuguese coast. Mar. Pollut. Bull. 58: 1130-1136.

Takeda, M.; Suno-Ikeda, C.; Shimabukuro, K.; Yoshida, M. \& Yokoyama, K. 2009. Mechanism of inhibition of the V-type molecular motor by tributyltin chloride. Biophys. J. 96: 1210-1217.

Tong, S. L.; Pang, F. Y.; Phang, S. M. \& Lai, H. C. 1996. Tributyltin distribution in the coastal environment of Peninsular Malaysia. Environ. Pollut. 91(2): 209-216.

Valdez Domingos, F.X; Azevedo, M.; Silva, M.D.; Randia, M.A.F; Freire, C.A.; Silva de Assis, H.C.\& Oliveira Ribeiro, C.A. 2007. Multibiomarker assessment of three Brazilian estuaries using oysters as bioindicators. Environ. Res. 105: 350-363. 
Braz. J. Aquat. Sci. Technol., 2012, 16(1):69-77.

Zaja, R.; Caminada, D.; Lončar, J.; Fent, K. \& Smital, T. 2008. Development and characterization of P-glycoprotein 1 (Pgp1, ABCB1)-mediated doxorubicin-resistant PLHC-1 hepatoma fish cell line. Toxicol. Appl. Pharmacol. 227: 207-218.

Submetido: Outubro/2010

Revisado: Abril/2011

Aceito: Abril/2012 